\title{
Study of Regional Economic Differences and Their Impacts
}

\author{
Xianwei Jia \\ Xi’an International University, Xi’an, Shaanxi, 710077
}

Keywords: Regional Economic Difference, Impact Study and Improvement

\begin{abstract}
In recent years, China's economic development rate has been three times as fast as the overall development of the world economy. The speed of China's economic progress is fast enough to attract the attention of the whole world. However, the progress of China's economy is not an overall improvement. Whether it is per capita income or the speed of economic development, there are large differences between regions. This phenomenon will not only bring more unstable factors to the society in a short period of time, but it is not conducive to China's goal of achieving sustainable development in the long run. Therefore, it is of great significance to strengthen the research on the status quo and influencing factors of regional economic growth differences at this stage.
\end{abstract}

\section{Introduction}

Regional economic development is a comprehensive category. From a horizontal perspective, it refers to the comprehensive development of all aspects of the economy in a certain period of time; from a vertical perspective, it shows the potential of economic development in the region and sustainable development. possibility. Gillis $\mathrm{M}$ and Perkins D H define economic development as an increase in per capita income and a fundamental change in economic structure. The American economist Michael P. Todaro believes that economic development is an overall change in society, including economic and non-economic content. Qi Chenglin believes that the difference in regional economic development refers to the phenomenon of non-equalization of the overall level of economic development in the per capita sense of each region of the country in a certain period of time. This paper believes that the regional economic development differences mainly include three aspects: 1 The spatial pattern of regional economic development differences, that is, the spatial difference of regional economic development in a certain time section; 2 The time evolution of regional economic development, namely regional economy The difference in the historical evolution of development in a continuous or a certain time interval; 3 the trend forecast of regional economic development, that is, the difference in regional economic development in a certain period of time in the future.

\section{Status of regional economic growth differences}

China's vast land and resources, each region has different advantages and conditions in the process of economic production. The existing conditions in some areas can be well adapted to the needs of the development of the current era, and thus the economic growth rate is relatively fast. In some areas, due to the late economic development and the constraints of natural and climatic factors, the current economic growth rate is very slow. First, observing the total GDP of China, we can find that the eastern region accounts for more than half of the total GDP, and this proportion is gradually increasing year by year. This phenomenon will inevitably lead to a decline in the economic proportion of the central and western regions. Regional economic differences are becoming increasingly apparent. According to valid data, in the mid-1980s, the proportion of the economy in the eastern part of China was only about twice that of the other two regions, but now it is nearly four times higher, and the regional economic differences can be seen. Secondly, from per capita domestic From the perspective of GDP, the per capita GDP of the three regions of the eastern, central and western regions is increasing in a stable state every year. However, compared with the 
three, a large difference can be found. In the past two decades, per capita GDP has increased by about 17 percent in the eastern part of China, while the central and western regions have increased by 14 percent and 15 percent respectively. Through this obvious data comparison, it is clear that the economic growth in the eastern region is much faster than the other two regions.

\section{Analysis of the Factors Affecting the Differences of Regional Economic Growth in China}

Capital has a relatively broad meaning. From a broad perspective, matter, manpower and land are important components. In the process of studying the factors affecting the regional economic growth in China, we can conduct research from the perspective of material capital, which includes both fixed and mobile forms of capital. The capital factor is one of the important factors affecting the regional economic growth difference. By comparing and comparing the total amount of various capitals in various regions, it is possible to measure the current status and speed of regional economic development.

Measuring the economic development of a region can also be carried out by investigating and calculating the employment rate in the region. This is the labor factor that affects the regional economic growth difference in China. The employment rate should be investigated by investigating the incumbent, the staff who receive the corresponding remuneration for social work, and the employees of the enterprise. Through the investigation of labor factors, we can grasp the current situation of making full use of labor resources in the region.

In the context of continuous advancement in science and technology, technology has become an important means of promoting economic growth. The extent to which an area adopts advanced technology can fully reflect whether the economic development of the region is consistent with the requirements of the development of the times, and is also an important manifestation of the economic development of a region. The impact of technological factors on China's regional economic growth is reflected in three aspects. First of all, the number of scientific and technical personnel. The greater the number of staff engaged in scientific and technological activities, the more favorable it is to the innovation of local science and technology. At the same time, the scientific and technical personnel also refer to those who provide relevant services for scientific and technological activities. The number of such staff is also the same to promote the regional economy and Scientific and technological progress is of great significance; secondly, funding for research and experimental development in the whole society. Including the introduction and purchase of various advanced instruments, labor costs and land construction costs. The more funds are spent, the more economic activities are carried out locally, and the economic benefits created are even greater; finally, the number of patent grants. The more developed and advanced the local economy and science and technology, the more helpful it is to create more innovative products and obtain patents under the authority of the State Intellectual Property Office. The more developed the economy, the more patented products there are.

\section{The impact mechanism of regional economic differences and the countermeasures to narrow the regional economic differences in China}

This paper applies the multi-level regression analysis model to quantitatively analyze the factors affecting regional economic differences (FDI), decentralization, marketization and investment level, in order to explore the internal reasons for regional economic differences. The multicollinearity test of the single-level model shows that the variance expansion factor (VIF) is greater than 2.5, indicating that the selected explanatory variables do not have significant multicollinearity. The results of the multilevel regression analysis are shown in Table 2. First, based on single-level likelihood ratio detection, the single-level model can account for $79.6 \%$ of the overall dependent variable, and there is a significant decrease from the single level to the double level $(\mathrm{P}<0.001)$, and there is also a significant reduction from the double level to the third level. $(\mathrm{P}<0.001)$. This shows that there is indeed a core-edge structure in our province, and it also shows that regional economic differences are affected by time points. FDI is often used as an important indicator of the degree of 
globalization. Since the reform and opening up, the scale of FDI entering China has become larger and larger, and China's economic development has also been affected by the export-oriented economy. However, the inter-regional distribution of FDI into China is very uneven. The Pearl River Delta region basically covers $90 \%$ of FDI, while the periphery of the Pearl River Delta only accounts for $10 \%$. The accelerated development of the Pearl River Delta region has occupied more resource advantages and deepened the development gap with the peripheral regions. The imbalance between the development of the Pearl River Delta and the peripheral regions has led to an imbalance in the distribution of FDI, and the imbalance in the distribution of FDI has deepened the gap between the Pearl River Delta region and its peripheral development. In this way, a regional cyclical cumulative causal effect is formed between FDI and regional economic growth. In the three levels of regression analysis models, FDI showed significant importance $(\mathrm{P}=0.027, \mathrm{P}=0.005$, $\mathrm{P}=0.011$ ), indicating that FDI has a direct effect on the expansion of regional economic differences in China. As an important indicator of globalization, FDI is becoming more and more important in China's economic development, especially after China's accession to the WTO. FDI has obvious policy and geographical location tendencies, and it is easy to form path dependence. In the core-edge structure, a large amount of FDI flows into the core area of the Pearl River Delta, accelerating the development of this area. In contrast, FDI in the marginal areas is rare, forming a sharp contrast. Therefore, FDI is one of the direct driving forces for the intensification of regional economic differences in China.

The study finds that there is a positive correlation between the decentralization of power in China and the development of regional imbalances. The simple decentralization of power includes two aspects. First, the decentralization of power is the expatriation of rights. It can stimulate the creative ability of market entities, promote the rapid growth of the local economy, better play local roles, stimulate the potential of domestic demand, and form new impetus. At the same time, the policy of decentralization and decentralization will help to improve the degree of marketization and give play to the role of the market in regulating economic growth; thus balancing regional development. First, the simple decentralization of power has prompted local governments to actively develop local economies. With the autonomy of financial power, local governments began to invest in infrastructure construction and public service facilities to promote economic growth while attracting foreign investment; however, this process often Promoting greater development in rich areas, but at the same time will also undermine the development of poverty-stricken areas; in addition, decentralization and decentralization often urge local governments to rely more on local fiscal revenues, leading to local protection and weakening the government's role in regulating the balance of resource utilization. Therefore, although the decentralization of the administration created an environment of rapid economic growth, it also indirectly increased regional differences.

By strengthening the specific analysis of the influencing factors of China's regional economic growth differences, it will help China to take effective measures in time to solve relevant problems in regional economic development and promote economic progress as a whole. First of all, to establish a scientific and effective regional economic development system, regional economic activities should be carried out around the system, and in the process of practice, continue to improve it, providing a strong guarantee for the long-term sustainable development of China's regional economy; second, strengthen Training of scientific and technological talents. In the new era, an important means to promote rapid economic growth is to use world-leading technology to increase production efficiency and reduce production costs, thereby generating greater economic benefits. Therefore, the training of scientific and technological personnel in the new era is of vital importance, and the scientific and technological personnel are the basis for the continuous advancement and innovation of China's technology.

\section{Conclusion}

China has always adhered to the idea of building a new China centered on economic construction. Through the efforts of the people throughout the country, China's economic development is getting faster and faster, but what follows is the growing regional economic growth. This situation will 
seriously hinder our country's sustainable development strategy. From the perspective of China's GDP and per capita GDP, it is possible to clearly observe the obvious differences in the economic presence between the eastern and central regions of China, and to strengthen the analysis of the factors affecting regional economic growth differences, which will help China in the new In the period, take effective measures to gradually shorten the differences, achieve overall progress, and lay a good foundation for sustainable development.

\section{References}

[1] Sun Xihua, Zhang Shumin. Research on Regional Economic Difference Analysis and Coordinated Development in Shandong Province [J]. Economic Geography, 2003, 23(5): 611-620.

[2] Qiu Fangdao, Zhu Chuanqi, et al. Analysis of the time and space characteristics of county economic differences in Jiangsu Province [J]. Economic Geography, 2004, 24 (4): 468-476.

[3] Pu Yingxia, Ge Ying, et al. Spatial Difference Analysis of Regional Economy Based on ESDA_—_Taking Jiangsu Province as an Example[J].Geographical Research, 2005, 24(6): 965-974.

[4] Shi Yilei, Lu Zhengnan. Regional Economic Differences and Coordinated Development Countermeasures in Jiangsu Province [J].Jiangsu Business Theory, 2005, (8):140-141.

[5] Zhao Yingxue. Research on the Economic Differences and Coordinated Development of Counties in Guangdong Province [J]. Economic Geography, 2003, 23(4): 467-471. 